\title{
Biological monitoring of workers exposed to 4,4'-methylenebis (2-chloroaniline) (MBOCA)
}

\author{
J D THOMAS' AND H K WILSON²
}

From the Health and Safety Executive,' Employment Medical Advisory Service, Bristol BS1 6AN, and the Occupational Medicine and Hygiene Laboratory, ${ }^{2}$ London NW2 $6 L N, U K$

ABSTRACT A biological monitoring programme has been developed for assessing occupational exposure to $4,4^{\prime}$-methylenebis (2-chloroaniline) (MBOCA) in a factory which manufactures polyurethane elastomers. In a systematic programme of biological monitoring over a five year period urinary MBOCA concentrations have been used to provide evidence of absorption of MBOCA. Improvements in the handling and use of MBOCA have coincided with a steady reduction in the urinary MBOCA concentrations.

Aromatic amines are in a class of chemical compounds that contain proved potent carcinogens. The chemical structure of 4,4'-methylenebis (2chloroaniline) (MBOCA) (fig 1a) is similar to benzidine (fig 1b), a diamine known to induce malignant bladder tumours in $\operatorname{man}^{1}$ and with a structural similarity to 3,3'-dichlorobenzidine, which has been shown to be carcinogenic in several animal species. ${ }^{2}$ In the mid 1950s MBOCA was introduced into the polyurethane industry and has since become a commercially important hardener or curing agent used in manufacturing certain isocyanate based polyurethane elastomers. Since MBOCA is an aromatic amine it has come under close toxicological investigation. MBOCA possesses the general toxic characteristics of aromatic amines and may produce cyanosis from methaemoglobin formation. ${ }^{3}$ Of greater concern are the results from animal bioassays in which it has been shown that MBOCA is carcinogenic in three animal species, rats, ${ }^{4}$ mice,${ }^{5}$ and dogs. ${ }^{6}$ In view of the animal data, and further evidence on the mutagenic ${ }^{7}$ and genotoxic ${ }^{8}$ nature of MBOCA, the compound has been cited as a potential human carcinogen. Munn suggested that MBOCA might be a potential bladder carcinogen in man. ${ }^{9}$ This comment was supported by Stula et al, ${ }^{610}$ who intimated that MBOCA and its structural analogues (benzidine and 3,3-dichlorobenzidine) were capable of inducing bladder cancer in dogs. There is no medical or epidemiological evidence

(C) Crown Copyright 1983

Received 8 August 1983

Accepted 17 November 1983 that MBOCA causes cancer in man, but it is worth noting that the average latency period of human bladder cancer is about 20 years.

Although the metabolic fate of MBOCA in man is unknown, unchanged MBOCA has been detected in the urine of workers who were occupationally exposed to the chemical. The metabolism and distribution of MBOCA have been studied in rats ${ }^{11}$ but no metabolites found in rats have yet been identified in human urine. Future studies may show that MBOCA metabolites are better biological indicators of absorption of MBOCA, but to date, unchanged MBOCA in urine has proved useful in monitoring programmes. In 1971 a survey of over 200 workers was reported and urinary MBOCA concentrations in the range 1-11 $\mu \mathrm{mol} / \mathrm{l}$ (about 10-1000 nmol MBOCA $/ \mathrm{mmol}$ creatinine) were recorded. ${ }^{12}$ Kinetic data on MBOCA uptake and elimination are limited. The report of an accident in 1978 , in which a worker was sprayed in the face with

a

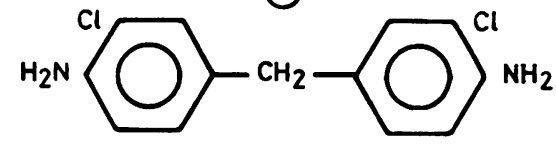

(b)

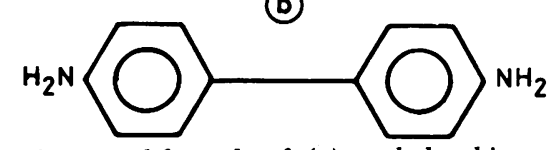

Fig 1 Structural formula of (a) methylenebis. (2-chloroaniline) and (b) benzidine. 
molten MBOCA, indicated that most of the material was excreted in the urine within 24 hours, with a peak excretion reaching about $600 \mathrm{nmol}$ MBOCA $/ \mathrm{mmol}$ creatinine. ${ }^{13}$

In 1972 the American Conference of Industrial Hygienists listed MBOCA as an "experimental carcinogen" and proposed a threshold limit value of $0.02 \mathrm{ppm}\left(220 \mu \mathrm{g} / \mathrm{m}^{3}\right) .^{14}$ In 1975 the ACGIH revised their classification and MBOCA was listed under "occupational substances suspected of oncogenic potential for workers." 1 s A discussion of the control measures that should be taken when handling MBOCA was presented by Henning. ${ }^{16}$ In 1978 the Health and Safety Executive recommended that the threshold limit value should be lowered from $220 \mu \mathrm{g} / \mathrm{m}^{3}$ to $50 \mu \mathrm{g} / \mathrm{m}^{3}$ (8h TWA). These limits referred to atmospheric levels of MBOCA, but since a possible route of absorption was believed to be through the skin it carried a skin notation. ${ }^{17}$ In the same year NIOSH proposed that no worker should be exposed to air concentrations in excess of $3 \mu \mathrm{g} / \mathrm{m}^{3} .^{18}$

In this paper we report the urinary MBOCA results from workers occupationally exposed to MBOCA over a five year period.

\section{Experimental details}

\section{FACTORY PROCESS}

The factory is in the United Kingdom and manufactures certain polyurethane plastics, which have good resilience and load bearing properties. Polyurethane is made from an isocyanate prepolymer and a curing agent. MBOCA is used as a curing agent that cross links the polymer chains. It is supplied as pellets, which are melted $\left(120^{\circ} \mathrm{C}\right)$ before being blended with the preheated liquid polymer. After pouring the molten mixture into a mould it is allowed to harden in an oven for about an hour. The articles are removed from the moulds and receive a final curing in an oven. The number of employees engaged in urethane production has been remarkably stable over the past five years. The company employs 12-15 men in a variety of tasks including handling the raw materials and molten MBOCA, preparing the polymer, removing products from the moulds, machining and handling the finished products, and general cleaning and maintenance. The men are trained in all aspects of the job and a rotation policy is in operation. Production of polyurethane products has been relatively constant over the five year period.

\section{BIOLOGICAL MONITORING}

In 1978 a systematic biological monitoring programme was initiated and the workforce were asked to provide regular monthly urine samples. These samples were collected from the entire workforce on the same day and dispatched immediately to the laboratory for analysis. Samples were deep frozen and analysed within three days. Using the method of Gristwood et al, ${ }^{19}$ without the hydrolysis stage, MBOCA was extracted from the urine with diethyl ether under alkaline conditions, and after derivatisation with heptafluorobutyryl chloride was analysed by electron capture gas chromatography. Creatinine in urine was measured using the Jaffe reaction on an autoanalyser.$^{20}$ The results were expressed in $\mathrm{nmol}$ MBOCA $/ \mathrm{mmol}$ creatinine (detection limit $1 \mathrm{nmol}$ MBOCA $/ \mathrm{mmol}$ creatinine; the coefficient of variation was typically $8 \%$ ). In addition, morning and afternoon urine samples were collected for five consecutive days from two process workers in October and November 1978. The same exercise was repeated in August 1981 with another worker who was engaged in general duties but was not handling MBOCA directly.

\section{Results}

The histogram (fig 2) shows the monthly group mean urinary MBOCA concentrations for all the workers. Maximum concentrations of MBOCA in the group were noted between July and September 1978 when the group average reached $50 \mathrm{nmol}$ MBOCA $/ \mathrm{mmol}$ creatinine. During this period peak concentrations of over $200 \mathrm{nmol} \mathrm{MBOCA} / \mathrm{mmol}$ creatinine were found in some workers. The results show a gradual improvement by January 1979, and by February 1980 the average concentrations level out at about $5 \mathrm{nmol} \mathrm{MBOCA} / \mathrm{mmol}$ creatinine. Further improvements are evident from December 1981. Although it is difficult to identify precisely what action resulted in a fall in urinary MBOCA concentrations, the relation between biological monitoring and some possible factors is illustrated in fig $3 a-d$. In 1978 the frequency distribution was broad with the workforce producing urinary results across the range $1-260 \mathrm{nmol} \mathrm{MBOCA} / \mathrm{mmol}$ creatinine (fig 3a). After improvements to the ventilation and the introduction of some protective clothing some improvement is seen in the urinary results. This is shown by a change in the histogram pattern where the modal value has been shifted to about $10 \mathrm{nmol} \mathrm{MBOCA} / \mathrm{mmol}$ creatinine (fig $3 \mathrm{~b}$ ). The pronounced improvements from late 1979 may be associated with the introduction of a dry cleaning scheme for the overalls. There was a significant increase in the number of workers who were found to have no MBOCA in their urine (fig 3c). From December 1981, after paying special attention to certain workers, most workers have no MBOCA in 


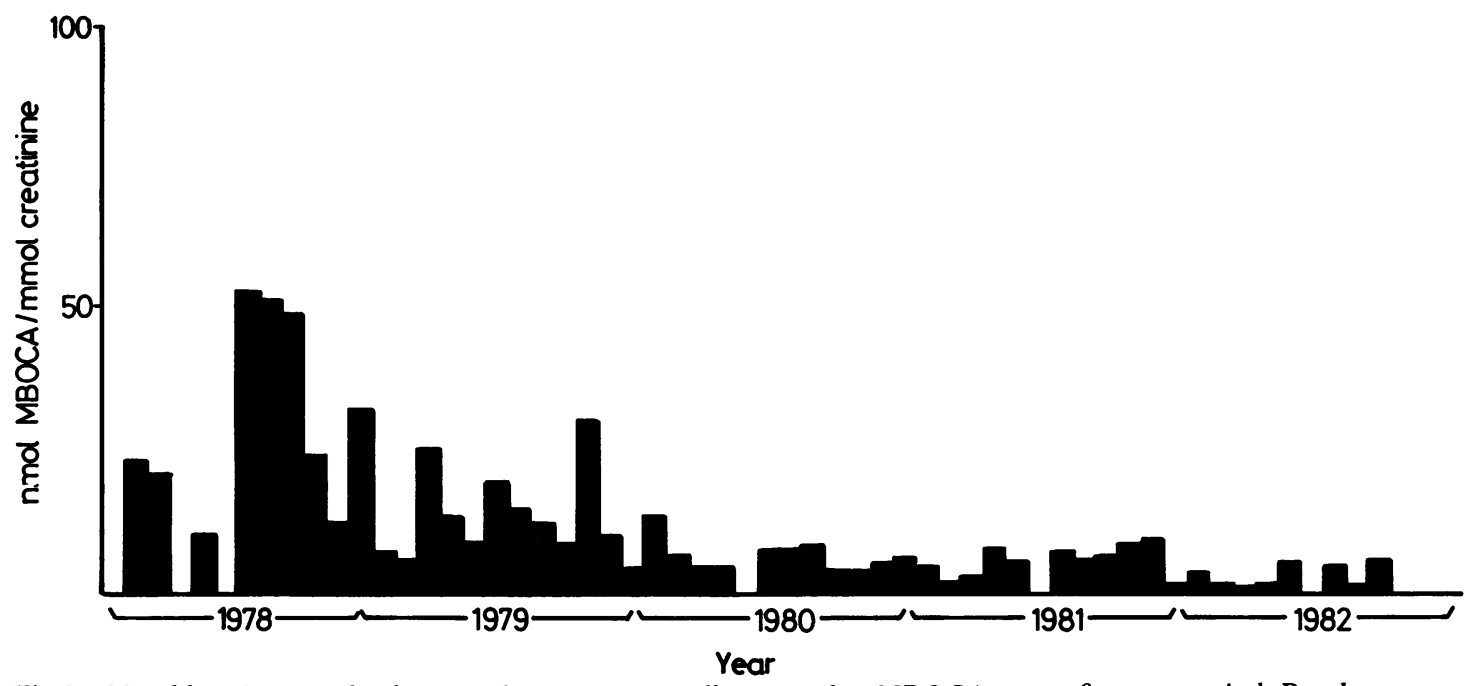

Fig 2 Monthly urine samples from workers occupationally exposed to MBOCA over a five year period. Results are

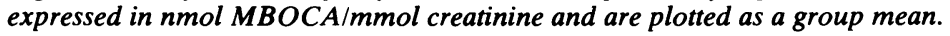

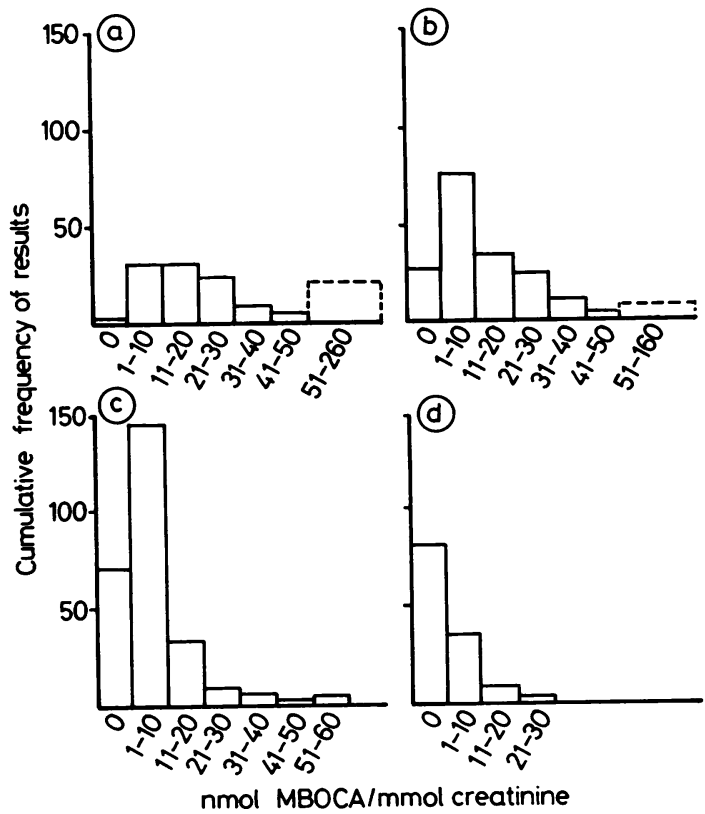

Fig 3 Frequency histogram of urinary $M B O C A$ analyses. (a) February 1978-November 1978. During this period ventilation improvements were undertaken and advice offered on the use of protective clothing; (b) January 1979-January 1980. Improved ventilation and some protective clothing was in use; (c) February 1980-November 1981. General factory hygiene improved, protective clothing was dry cleaned regularly; and (d) December 1981-October 1982. Special attention was paid to workers with raised urinary $M B O C A$. their urine and only a few exceed $10 \mathrm{nmol}$ MBOCA $/ \mathrm{mmol}$ creatinine (fig $3 \mathrm{~d}$ ).

In an attempt to identify problem areas within the factory two process workers with consistently high urinary MBOCA concentrations were monitored twice daily for one week on two separate occasions in October and November 1978 (fig 4a, b). In October both workers had significantly raised MBOCA concentrations in the urine $(180 \mathrm{nmol}$ MBOCA $/ \mathrm{mmol}$ creatinine) towards the end of the week. On repeating the exercise in November the highest concentrations were observed at the beginning of the week.

Analysis of the data from individual workers shows that certain men have frequent excursions well outside the group average. This fluctuating response in one individual is illustrated in fig 5 . Two excessive values were recorded in July 1978 and in October 1979 (176 nmol MBOCA/mmol and 161 nmol MBOCA $/ \mathrm{mmol}$ creatinine respectively). On several occasions concentrations of $50 \mathrm{nmol}$ $\mathrm{MBOCA} / \mathrm{mmol}$ creatinine were noted; however, from October 1981 to October 1982 the excretion of MBOCA had fallen to a mean value of $8 \mathrm{nmol}$ MBOCA $/ \mathrm{mmol}$ creatinine. This worker, who was not handling MBOCA, was monitored twice daily for a full working week in August 1981, and a detailed account of his work pattern was taken. The urinary values reached a maximum of $30 \mathrm{nmol}$ MBOCA $/ \mathrm{mmol}$ creatinine midweek and fell again towards the end of the week (fig 4c). A careful 


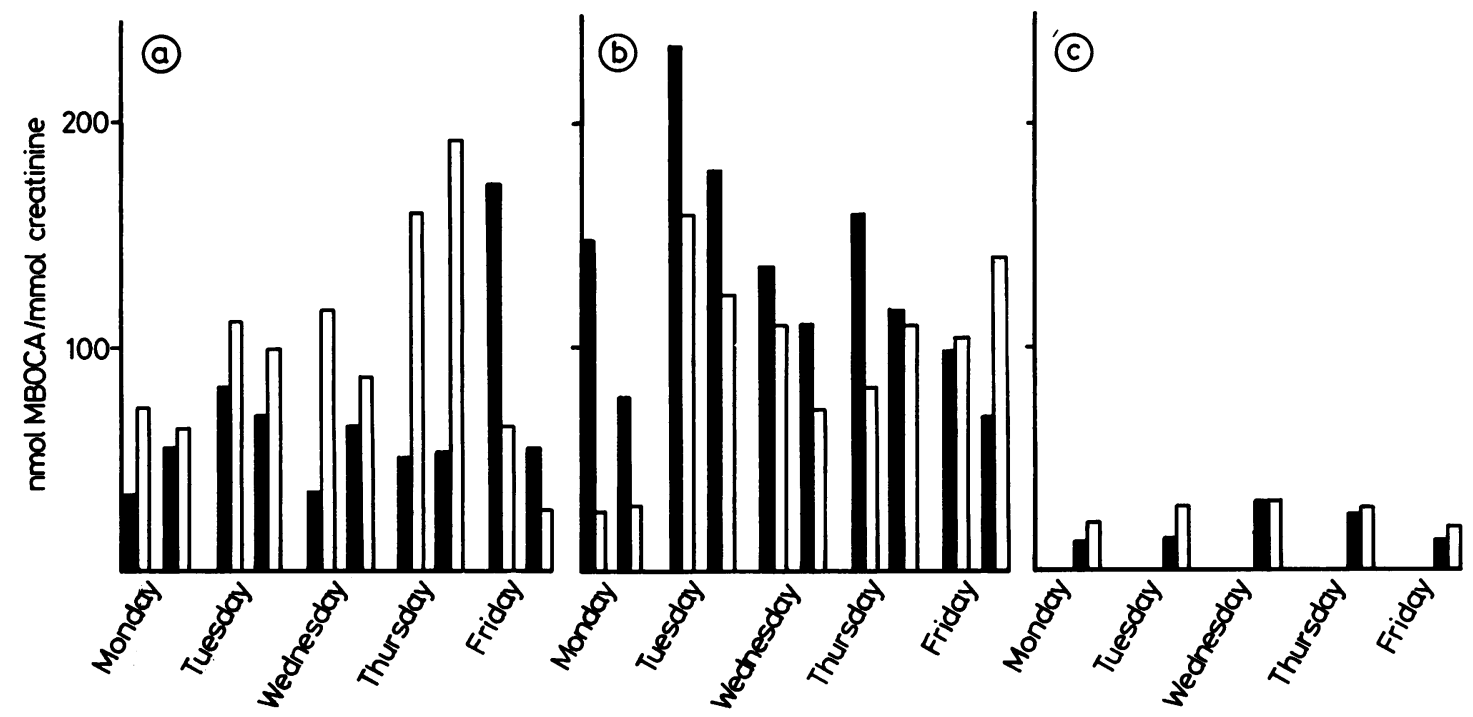

Fig 4 Urinary MBOCA in morning and afternoon samples for five consecutive days from two workers. Worker A open columns; worker B dark columns. Tests were carried out in October (a) and repeated in November (b) 1978. Figure 4c presents results from a third worker who was monitored twice daily in 1981.

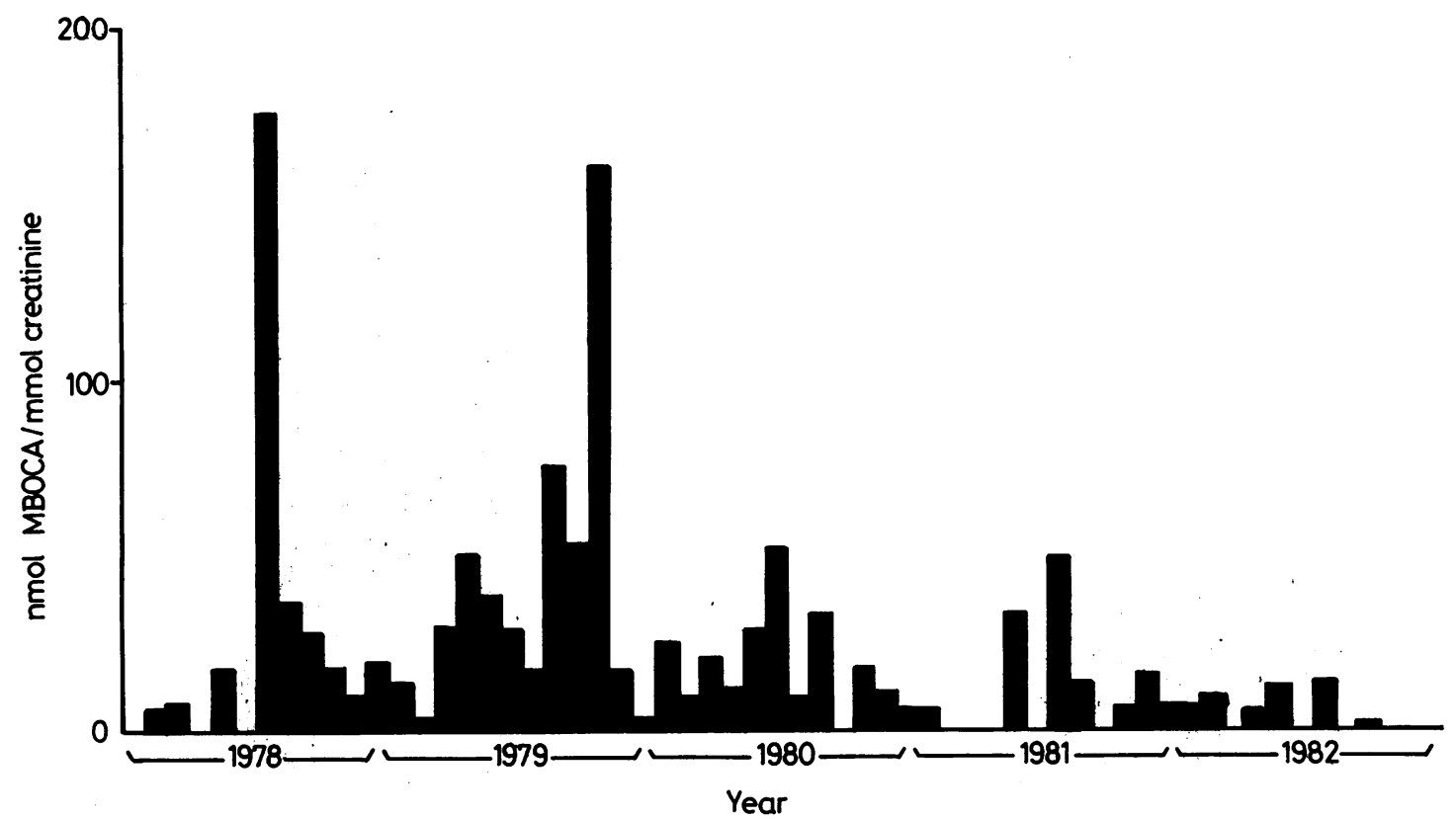

Fig 5 Urinary MBOCA concentrations in one worker over a five year period (monthly samples). 
examination of the tasks he performed did not appear to correlate with the raised MBOCA concentrations.

\section{Discussion}

A biological monitoring strategy has been used to help reduce occupational exposure to MBOCA. Although general improvements in factory hygiene and the use of protective clothing reduced the potential for absorption, biological monitoring was used to assist in identifying workers whose standard of personal hygiene was inadequate or who were being exposed to MBOCA from a source that was not obvious. We observed that one worker who had consistently raised MBOCA concentrations in his urine was not handling MBOCA directly. His duties included general cleaning and degreasing and burning waste plastic. The fumes of burning plastic contain significant amounts of MBOCA, and this operation may be a potential source of exposure. In addition, it was observed that as a result of this worker's cleaning and degreasing duties his overalls became contaminated with solvent and process residues; he was frequently observed to be wearing dirty overalls open at the chest. His personal exposure and absorption was reduced only when his duties were changed. By trying to reduce skin and surface contamination the overall group average MBOCA urinary concentrations fell to less than $5 \mathrm{nmol}$ MBOCA $/ \mathrm{mmol}$ creatinine, and since December 1981 most workers have no detectable amounts of free MBOCA in their urine.

As yet, little is known regarding the kinetics and metabolism of MBOCA in man. We have noted that rapid fluctuations occur throughout the working week. MBOCA is probably metabolised in man and the use of these metabolites for monitoring absorption of MBOCA into the body may be more appropriate than measurement of unchanged MBOCA. ${ }^{19}$ Although the significance of the urinary MBOCA results is unknown it would seem prudent to minimise exposure by operating in a clean dust free and fume free environment and to use adequate protective clothing that is regularly cleaned so that all possible routes which may lead to skin absorption may be reduced to a minimum. We conclude that a regular biological monitoring surveillence programme can help identify any deviation from the recommended operating procedures.

We value the helpful advice of HM Factory Inspectors and medical colleagues in the Health and Safety Executive (South West Region).

\section{References}

' Zavon MR, Hoegg U, Bingham E. Benzidine exposure as a cause of bladder cancer. Arch Environ Health 1973;27:1-7.

${ }^{2}$ International Agency for Research in Cancer. Monographs on the evaluation of the carcinogenic risk of chemicals to humans. Lyon: IARC 1982;29:239.

${ }^{3}$ Ryan JD. MOCA* and LD-813: diamine curing agents for isocyanate-containing polymers. Du Pont Chemicals, 1977. (Trade bulletin.)

${ }^{4}$ Kommineni C, Groth DH, Frockt IJ. Determination of tumorigenic potential of methylenebis o-chloroaniline.J Environ Pathol Toxicol 1978;2:149-71.

${ }^{5}$ Russfield AG, Homburger F, Boger E, Van Dongen CG, Weisburger EK, Weisburger JH. The carcinogenic effect of 4,4'methylenebis (2-chloroaniline) in mice and rats. Toxicol Appl Pharmacol 1975;31:47-54.

- Stula EF, Barnes JR, Sherman H, Reinhardt CF, Zapp JA. Urinary bladder tumours in dogs from 4,4'methylenebis (2chloroaniline) (MOCA).* J Environ Pathol Toxicol 1977; 1:31-50.

${ }^{7}$ McCann J, Choi E, Yamasaki E, Ames BN. Detection of carcinogens as mutagens in the salmonella/microsome test: assay of 300 chemicals. Proc Natl Acad Sci USA 1975;72:5135-9.

${ }^{8}$ McQueen CA, Maclansky CJ, Crescenzi SB, Williams GM. The genotoxicity of 4,4'-methylenebis(2-chloroaniline) in rat, mouse and hamster hepatocytes. Toxicol Appl Pharmacol 1981;58:231-5.

${ }^{9}$ Munn A. Occupational bladder tumours and carcinogens: recent developments in Britain. In: Lampe KF, ed. Bladder cancer. Birmingham, Alabama: Aesculapius Publishing Co, 1967:187-92.

${ }^{10}$ Stula EF, Barnes JR, Sherman H, Reinhardt CF, Zapp JA. Liver and lung tumours in dogs from methylenebis (2-chloroaniline). $J$ Environ Pathol Toxicol 1978; 1:339-56.

" Farmer PB, Rickard J, Robertson S. The metabolism and distribution of 4,4'-methylenebis (2-chloroaniline) (MBOCA) in rats. J Appl Toxicol 1981;1:317-22.

12 Linch AL, O'Connor GB, Barnes JR, Killian AS, Neeld WE. Methylenebis o-chloroaniline (MOCA). Evaluation of hazards and exposure control. Am Ind Hyg Assoc J 1971;32:802-19.

${ }^{13}$ Hosein HB, Van Roosmalen PB. Acute exposure to methylenebis 2-chloroaniline (MOCA). Am Ind Hyg Assoc J 1978;39:496-7.

14 American Conference of Governmental Industrial Hygienists Committee on Threshold Limits. Threshold limit values for chemical substances and physical agents in workroom environments with intended changes for 1972. Cincinnati: ACGIH, 1972:39.

is American Conference of Governmental Industrial Hygienists Committee on Threshold Limits. Threshold limit values for chemical substances and physical agents in the workroom environment with intended changes for 1975. Cincinnati: ACGIH, 1975:42.

${ }^{16}$ Henning HF. Precautions in the use of methylene bis-o-chloroaniline (MBOCA). Ann Occup Hyg 1973;17:137-42.

${ }_{17}$ Health and Safety Executive. Threshold limit values for 1977. London: HMSO. 1978. (Guidance note EH15/77.)

18 Department of Health, Education and Welfare, National Institute for Occupational Safety and Health. Special hazard review with control recommendations: 4,4'-Methylenebis (2-chloroaniline). Cincinnati, Ohio: DHEW (NIOSH) 1978. (Publication No 78-188.)

${ }^{19}$ Gristwood W, Robertson SM, Wilson HK. The determination of 4,4'-methylenebis (2-chloroaniline) (MBOCA) in urine by electron capture gas chromatography. J Anal Toxicol (in press).

${ }^{20}$ Henry RJ, Cannon DC, Winkleman JW. Automated determination of serum and urine creatinine. In: Clinical chemistry, principles and technics. Maryland: Harper and Row, 1974:552-5.

*MOCA is Du Pont's registered name for 4,4'-methylenebis (2chloroaniline). 